\title{
Cultural Dimensions of Workfare and Welfare
}

Journal of Comparative Policy Analysis, 2005, 7 (3), pp.233-247

\author{
David Bartram \\ Department of Sociology \\ University of Leicester \\ University Road \\ Leicester LE1 7RH \\ England \\ d.bartram@le.ac.uk
}




\begin{abstract}
I compare the treatment of two marginal recipient groups, not commonly regarded as "on welfare," to that experienced by conventional welfare recipients and argue that we need an understanding of welfare that takes culture more seriously. Public discourse concerning welfare would be more enlightening if we could move beyond hegemonic concepts such as "economic self-sufficiency." I propose thinking of welfare as a public subsidy for groups whose way of life is incompatible with economic self-sufficiency - an approach that enables us to consider culture explicitly in debates regarding the core populations affected by social policy.
\end{abstract}


Scholars studying welfare have often identified a profound ambivalence in American attitudes to the welfare state: supporters of the welfare state, in particular, struggle to balance a pragmatic humanitarianism and sympathy with their adherence to traditional values of economic individualism (Feldman and Zaller 1992; see also Heclo 1986). But welfare state detractors are not immune to this sort of internal conflict: it is especially apparent in the writings of Lawrence Mead, one of the foremost proponents of workfare. In a final-chapter response to critiques by British authors concerning his proposals for workfare and welfare reform, Mead makes a startling statement, almost in passing, on his very last page: "the mother's caring for children has value. In deference to that, I would require her to work only half-time, even if this meant she had to stay partially on welfare" (1997: 133). The suggestion - a substantial qualification of his main proposal for workfare - does not receive further exploration, and to my knowledge it does not appear in his other writings on the subject.

One goal of this paper is to argue that this ambivalence is more complex than is commonly understood. In particular, observers have not given proper consideration to the role of culture (in the sense of ways of life) when trying to understand why people hold particular beliefs about welfare. As noted, scholars have pointed to a conflict between individualist and humanitarian values. This conflict, however, is mediated by attitudes to the particular groups that receive welfare. More specifically, people make judgments, positive and negative, about the culture of those groups, such that their views about welfare in practice are probably different from the views they might hold regarding welfare as an abstract, general topic.

The ambivalence in attitudes to welfare is linked to another type of ambiguity that also connects with cultural concerns. Mead's central theme is that welfare recipients must be made to "work" - which implies that they are not doing so already. What he and others writing in a similar vein really mean is that welfare recipients must be made to find paid employment. The 
slippage between these two concepts - work and employment - is rooted in a phenomenon Marx described as the fetishization of money. For some, "work" is any activity for which one receives a wage or salary in return; in other words, it is the money that defines the work. When we start instead from a "real" understanding of work (see for example Benería 1988), it is easy to recognize that the bulk of the welfare population - consisting, as much of it does, of single mothers - is already well engaged in work.

When we discuss welfare recipients, why is the work mothers do so difficult to recognize as work? Books such as Hochschild's The Second Shift (1990) would seem to have made it impossible not to do so; in addition, Mink (1998) and others have proposed a social wage for (mainly) women's work in the home. But this understanding has penetrated popular and scholarly consciousness to different degrees for different populations; the default characterization of welfare recipients draws heavily on the assumption that such people are on welfare because they do not work.

Again, the argument here is that the difficulties described so far are essentially cultural in nature, rather than solely economic. The work done by most welfare recipients is not recognized as such because the cultural context of that work - single motherhood, "broken homes," "illegitimacy" - erodes the foundation of that population's claim for recognition as contributing members of society. When one receives a wage, no one will dispute that one is actually working. But many kinds of work are not rewarded with wages; in these cases recognition of contribution and value will depend heavily on judgments made regarding the cultural context of the work.

To clarify and defend this perspective, I offer a new way of seeing welfare: as a public subsidy that supports ways of life that are at least in part incompatible with economic selfsufficiency in market-dominated societies. This perspective can be contrasted with a more conventional view, in which welfare consists of specific programs whose purpose is to prevent or 
alleviate poverty. This new definition arises from consideration of instances of non- or partiallywaged work performed by groups that are recognized as legitimate and valuable - so much so that they are rewarded with state subsidies that are reasonably conceived as welfare. The process by which such subsidies are won is political - but the political power of those who claim support is enhanced when claims to legitimacy are successful. This sort of perception has an important cultural dimension.

In other words, claims for welfare - as well as the reactions to those claims - are strongly conditioned by cultural features of the group making the claim. Discourses of welfare reform are frequently grounded in a hegemonic value: economic self-sufficiency (Feldman and Zaller 1992). A primary goal of this paper is to show that this value is an inadequate basis for policy and reform proposals: this perspective is myopic for being excessively economistic and for failing to recognize the significant role played by judgments regarding culture.

To bring culture to the forefront, I will first describe what may be considered as marginal cases of welfare, that is, instances of state support for groups that are not normally considered as “on welfare.” Comparing these cases, where dynamics relating to culture are obvious and unmistakable, will help us come to see the same dynamics in the case of conventional welfare recipients as well, where long-dominant perspectives reinforce a tendency to see only political and economic dimensions. The initial focus on marginal groups is deliberate: we are accustomed to seeing conventional welfare recipients in particular ways, and to help transcend the limitations of such perspectives and develop new ideas, I propose first to describe groups for whom the dynamics to be explored stand out in sharp relief. Later in the paper I draw parallels between the marginal cases and the more conventional recipients; even if these dynamics in relation to the latter are less pronounced, I will argue that comparing them to conventional recipients leads us to important insights regarding the latter. 
One example comprises a significant population of ultra-Orthodox Jews in Israel. In many of these families, the men generally do not hold paid jobs, choosing instead to engage in full-time religious study for many years. Their wives sometimes do waged work, but they also bear large numbers of children and their work histories are often intermittent at best. Even when working, their incomes are generally not sufficient to support their families. Given these choices, these families survive only because of extensive state support.

Another case is French farmers (though the point could be extended to farmers in other wealthy countries). ${ }^{1}$ This is of course a population that does work in an obvious sense. Nevertheless, the work is not in itself sufficient to provide an adequate income; many French farmers survive as such only because they receive significant income support from the public. It is illuminating to consider this income support under the heading of welfare, insofar as it is a crucial condition enabling this population segment to pursue their chosen way of life, much as in the previous example.

It could be argued (and often is) that the "need" for public support in both examples is given in the choices each group makes concerning how to focus their efforts on particular activities. In both cases individuals choose to engage in activities that preclude "normal" work of the sort that would provide a reasonable income and thus obviate the need for state support. In a critical mode, this perspective amounts to a claim that these individuals do not in fact need welfare; instead, they ought to choose to live differently, so that they can support themselves. Whether or not one thinks in that critical mode, one can certainly imagine that it would be possible for them to do so, that is, to make different choices about how to live so as not to be a "burden" on the public purse.

Discussion of the examples in this paper is meant to contribute to an expanded vocabulary for debates on welfare and workfare, in particular by laying bare the cultural 
dimensions embedded in claims that particular groups either deserve welfare or should support themselves. I will argue that, although economic self-sufficiency is frequently propounded as the overwhelmingly dominant value in social policy, other values are demonstrably important and are indeed embodied in existing policies and public attitudes. Public discourse is dominated by values that can be recognized in markets; it is more difficult to perceive and express other types of value. By describing the chosen examples and then drawing parallels with conventional recipients, I hope to facilitate an enrichment of public and scholarly discourse and to provide a language for discussion of values that in the absence of such a language are currently difficult to perceive. The ideas come from consideration of cases not commonly considered as "welfare", but the goal is then to apply those ideas to some of the central scholarly and political debates regarding the conventional groups.

\section{Theoretical Prelude}

What is welfare? In this paper I take a quite broad view. Barry (1999) cautions against equating "welfare" (well-being) with the "welfare state": the latter might not always contribute to the former, a point appearing in a multitude of critiques of the welfare state from diverse points of view. Even when we focus on the welfare state, however, there is a tendency to assume that it comprises the activities performed by institutions that are obviously engaged in welfare in a lay sense of the word (for example, unemployment benefits, food stamps, Medicaid). This approach, usually implicit, uses the contingencies of existing practices to determine the definition of a concept. Surely it is better to begin with the concept itself, looking beyond practices to attempt to elaborate a coherent logic.

In that mode, a useful definition for the purposes of this paper comes from Blau and Abramovitz, who characterize "social welfare policy" as an "arena of struggle" over "the 
distribution of societal resources" (2004: 38). This definition includes conventional programs that provide income support and other goods and services to people whom we conventionally think of as "on welfare," but it encompasses much more, including fiscal policy and other policies that have welfare impacts. For example, transportation policies have distinct welfare implications, especially (but not only) in relation to poorer people who might not be able to afford cars. Although it might be objected that in this view welfare is potentially anything, the approach makes sense when one is willing to relinquish the notion that welfare is simply what bureaucrats label as such in a particular policy setting. It is also more sensible to consider policies in relation to their impact - what they actually do - than to try to discern their purpose or the intentions of those who created them; intentions are frequently frustrated in implementation, and important consequences are often unintended. Some programs have substantial welfare impacts even if they were not created as "welfare programs." Finally, a broad approach is necessary for comparative analysis; we cannot allow our ideas to be constrained by the practices of any particular state, given that different countries work with different modes and institutions.

The paper invokes a similarly broad view of culture. A useful definition comes from Abercrombie et al.: "the total set of beliefs, customs or ways of life of particular groups" (1984: 99). Ideologies and values systems are components of culture in this approach; they are not exhaustive of it. The everyday sense of the term - ways of life - is sufficient for purposes here. ${ }^{2}$ As noted above, the intention is to analyze "marginal" groups to highlight features of their experience that we are not accustomed to seeing in the experience of more "conventional" recipients of welfare. I then explore the more general question concerning the relationship between welfare and culture, in regard to more conventional recipients.

A familiar scholarly discussion of welfare asserts that welfare policies allow workers to resist, to varying degrees, the capitalist imperative to commodify labor (Esping-Andersen 1990). 
Social policies such as unemployment benefits, minimum wages, and family allowances (among many others) ensure that many people, despite owning next to nothing but their labor power, can survive without paid work under certain circumstances. This protection from the vagaries of the labor market reduces uncertainty and vulnerability; it also improves workers' bargaining position vis-à-vis capital. This latter issue is a matter of providing those who are not wealthy with alternative means of income or survival, alternatives that would not be available through an unregulated ("free") market. Thus is labor partially "decommodified." In this understanding, welfare is about much more than preventing people from being poor: rather than simply supporting consumption, welfare has significant effects on production as well, that is, how people (and societies) organize their productive activities. Specifically, it enables people to avoid particularly unattractive work (in terms of the activity itself, not simply the wage).

The provision of alternatives to paid employment is precisely what some critics of the welfare state object to. One strand of popular thought is that people who receive welfare are simply lazy - they could work if they had to but, since they don't have to, they choose not to. Scholars such as Charles Murray (1984) have provided academic backing for this view, describing how at certain times and places welfare (at least in the US) has provided greater resources than one could acquire by working at a low-level job. In such situations, Murray argues, not working is simply the rational thing to do. This theme is continued in more recent writings, such as Tanner (2003).

The social democratic view and the conservative critiques are united in at least this aspect of their understanding of welfare: the existence of welfare policies allows people a greater range of choices about how they live, so that many make decisions in this regard that are different from the "default option" - work at any price the market determines - that would otherwise define 
their lives. A central difference between progressives and conservatives is whether one regrets or welcomes this added degree of choice.

But both types of scholars seem to pass over an important element of the above description, that is, the final three words, "how people live." In highlighting that element we can see that there are specifically cultural dimensions of social policy.

Culture is of course not the only important issue. Global economic changes in recent decades have had a significant impact on the welfare state, contributing to retrenchment in many places (Brown 1988, Mishra 1999). There is particular concern in Europe that generous benefits reduce labor flexibility, contribute to structural unemployment, and thus inhibit economic restructuring and growth. Flexibility and restructuring are understood to be necessary in a context of increasingly globalized trade and investment regimes. Given that this form of analysis is correct in its overall outline, it is important not to overstate its conclusions: for one thing, Huber and Stephens (2001) argue that the prevalence of veto points in policy regimes has meant that retrenchment has typically been modest. In addition, it is surely important to explore exceptions to dominant trends - in other words, cases (such as those described here) that have not succumbed to tendencies identified as universal in a scholarly consensus.

A primary goal of this paper is thus to analyze an important but overlooked respect in which welfare policies - broadly conceived - increase or maintain a range of choices regarding how people live (and work). The key to this exercise is to expand our understanding of what should be described as "welfare." Income support is provided to certain categories of people not commonly - but reasonably - described as "welfare recipients." This support sometimes makes it possible for people to live in ways that do not meet normal expectations of economic selfsufficiency. Welfare has important consequences for cultural dimensions of societies, not just economic dimensions. Examples follow. 


\section{Ultra-Orthodox Jews in Israel: Jobs versus religion}

The political and military conflict between Israel and the Palestinians overshadows several important divisions within Israeli society. One of the most politically salient of these involves the multi-dimensional conflict between secular and religious Jews. The animosity between those who are firmly secular and those who are fervently religious is perceived as a destabilizing force in Israeli politics (Horowitz and Lissak 1989).

One of the key points of conflict relates to what secular Israelis perceive as ultraOrthodox exploitation of the welfare state (and their concomitant "laziness"). Other issues as well generate widespread antagonism toward the ultra-Orthodox: their failure to provide military service and their attempts to impose religious obligations on the entire (Jewish) society are the other primary flashpoints. The issue of welfare, however, is troubling for many secular Israelis because they feel it reaches directly into their pockets.

The social policy provisions for ultra-Orthodox families are a welfare critic's nightmare. As indicated above, a substantial degree of state support enables these families to survive without engaging in paid work. This support takes a variety of forms. One primary source of support is "welfare" in a straightforward way: child support payments. These payments are offered on behalf of all children in Israel, but the arrangements have been specifically tailored to suit the demands of the ultra-Orthodox (hereafter referred to with the more concise Hebrew word Haredim). Families receive 170 shekels (New Israeli Shekels, NIS; approximately US\$40) monthly for each of the first two children. In many countries, payments for additional children get progressively smaller (as the marginal cost of caring for each additional child is lower) - but in Israel those payments instead increase quite dramatically. Under the Large Families Law 
(passed in 2000 but revoked in 2003), families received an additional NIS850 (approximately \$195) for their fifth child and every child thereafter. ${ }^{3}$

There are other benefits as well. Haredim receive direct government payments and benefits for studying in yeshiva, including health insurance. There is heavily subsidized day care and extended school hours. They receive very significant discounts on their tax liabilities as well as mortgage subsidies and rent supplements. Ilan (2000) estimates that a Haredi family with six children receives payments (including tax abatements) amounting to NIS6500 a month ( \$1450), as against the monthly minimum wage of NIS3300 (\$800). A family of ten would receive the equivalent of $\$ 2250$. These figures are net of tax; a six-person household with employed members would need gross earnings of approximately $\$ 2200$ to be left with take-home pay of $\$ 1450$ - as compared to an average gross Israeli wage of approximately $\$ 1500$. The Israeli welfare state has not been immune from pressures deriving from global economic changes, and the revocation of the Large Families Law shows that there has been some retrenchment. But even if child support payments have been cut back from the higher levels provided in 2000, they still provide substantial benefits for Haredi families - as do the other arrangements described here.

One of the key components feeding demand for these arrangements is the issue of military service. All Jewish Israelis are, in principle, expected to serve in the army for three years (for men; two years for women). The Haredim are unwilling to do so: they are not satisfied that the food served by the army is sufficiently kosher, and they believe there is too much mixing of the sexes. More fundamentally, they believe that army service is a distraction from the calling that God demands of them: Torah study. Under arrangements created for very small numbers in 1948 and then extended greatly after Likud overthrew Labor in 1977, they are therefore exempted from conscription; more precisely, they receive rolling deferments. The number of deferments - 29,000 in 1998 - provides a rough proxy measure for the number of families whose 
male head is engaged in full-time Torah study instead of paid employment (Sheleg 2000). ${ }^{4}$ Some Haredi men do work, but full-time study is the ideal.

This approach to military service creates difficulties when they pass the normal age for regular conscription (as distinct from reserve service), for two reasons. First, many employers specify that prospective employees must have completed their military service. It is widely understood that the primary purpose of this restriction is to discriminate against Arabs (that is, Israeli citizens, whom the army nonetheless does not want in its ranks), but it affects Haredim as well. Second, the regulations exempting Haredim from army service specify that to maintain the exemption they must engage in full-time religious studies; if they take employment, they would then be subject to conscription, for a brief regular service and then for reserve duty.

An additional factor inhibiting employment of Haredi men is their education as children, which is almost exclusively religious in content; teaching of "secular" skills is almost entirely absent at the secondary level, especially for boys. Many Haredim are therefore unemployable for all but the most unskilled positions. From a secular perspective this aspect of their situation is deplorable, but it is not seen as a problem by the Haredim themselves: again, their true calling is Torah study, and paid employment (and secular education) would be a distraction.

The emphasis Haredim place on study over work is rooted in what they hold to be religious requirements. Stadler (2002) shows that this version of Judaism is heavily imbued with the notion of predestination, at least with regard to worldly outcomes: Haredim believe that one's economic circumstances are the product of the divine will and even of miracles. To the extent that one's own efforts play any role, it is study, not work, that is presumed to bring God's favor.

For secular Israelis, this complex of state support and absence from the labor market is costly in two respects. First, the benefits received by Haredim are funded by taxpayers, and money spent this way is not available for other purposes. Second, because they are not 
employed, Haredim are not themselves taxpayers to any significant degree (apart from VAT). There are clearly net gainers and losers here, in fiscal terms. From this perspective, Haredim do not "work," and their decisions not to work are made possible by welfare programs that they abuse, in particular by having large families that they cannot support with their own efforts.

The secular perspective here is consistent with a common-sense understanding of how one must order one's life in a liberal capitalist society. The core liberal value is economic selfsufficiency of individuals. It is obvious that Haredim hold other values to be more important.

The Haredi response, usually implicit, to the secular critique draws on themes familiar from discourses of multiculturalism in other contexts. In particular, the demand for economic self-sufficiency is seen as a threat to their way of life, their culture, which is held to be valuable in its own right, worthy of preservation even if it imposes economic costs on the society as a whole. In other words, the demand that Haredim behave like other, more "normal" members of Israeli society - holding regular jobs, in particular - would have consequences not just in economic terms but in cultural terms: they would cease to live in what they understand to be their traditional and required ways. ${ }^{5}$ The demand for economic self-sufficiency is in effect a demand for the end of Haredi culture as such. In addition to the fact that Haredi men do not want to spend their days working in a normal paid job, there remains the fact that one cannot simply "go out and get a job." Their lack of a normal secular education is probably the most important barrier, but there are others as well, including the antipathy felt towards them by many secular people, who are usually the gatekeepers into employment. Education is particularly important, however, because of the fact that education does not simply prepare one for employment but instills particular cultural traits. Secular education, essential preparation for secular employment, is anathema to this fervently religious population. In the end, there is a plausible argument that the overriding function of the arrangements the Haredim have constructed for themselves is quite 
simply the preservation of their way of life - in particular, by way of maintaining strict separation between themselves and the secular society (Stadler 2002, Heilman 1992, Berman 2000). ${ }^{6}$

\section{French Farmers on Welfare}

In the preceding section I do not assert that the subsidy for Haredim is actually legitimate. Rather, the point is simply to demonstrate that the central issue at stake is culture, not poverty. I continue in that vein here, turning to another case, that of French farmers. Again, I could have chosen farmers in other wealthy countries as well, but the French case is the most developed along the lines I will discuss. In particular, French agricultural policy seems to go the furthest in attempting to preserve small- and medium-scale family farming, a sort of peasantry. ${ }^{7}$ It thus makes more sense here than elsewhere to think about a farming subsidy as a mechanism for preserving a way of life, a set of cultural qualities.

As indicated above, French farmers survive as farmers only because of a host of subsidies. Some of these are direct government payments, but the biggest subsidy is extracted from consumers via controls on imports of agricultural goods from low-wage countries: Franklin (1988) estimates that consumers directly provide approximately $60 \%$ of overall support (while in the US the support comes more from direct payments out of tax revenues). Here the impact of global economic changes common in other sectors would appear to be quite limited: export subsidies and import restrictions have not been dismantled, despite calls from the developing world for implementation of policies that reflect the hegemonic rhetoric of free trade.

There is no dispute concerning the fact that what farmers do, the activity that the subsidy facilitates, is work - though we will see shortly that the obviousness of the point masks an important subtlety. The more difficult part is to argue that this subsidy constitutes a form of 
welfare. I contend that this categorization makes sense, insofar as this case bears significant similarities to the previous one. One does not normally start with the premise that farmers receive a subsidy because they are poor. ${ }^{8}$ But there is no more reason to reject this premise in the case of farmers than in any other case. Without the subsidy component of their income, they would indeed be poor - so poor, in fact, that most would probably leave this occupation for another. Instead, farmers demand a subsidy precisely because they don't want to leave this occupation for another, or perhaps because their education and experience would make it difficult (though surely not impossible) for them to find other types of work.

Their success in this regard contrasts starkly with the way economic and technological change drives occupational change in other spheres. In most sectors, increasing productivity (particularly for products with low income-elasticity, such as food) means that fewer workers are required to produce the goods; excess supply results in falling prices (wages), and so workers seek more lucrative employment elsewhere. A classic example is telephone operators, who have been largely replaced by computers (switches). The same sort of transformation has taken place to a certain extent in agriculture, such that farmers are often referred to as "victims of their own success": farming productivity has continued to rise very impressively. But their resistance to the normal employment implications of this process has been more effective than in other sectors.

The crucial condition enabling farmers to act on their preference is that they succeed in pressing their case in the political sphere. Their claim for support resonates with a sense of shared self-understanding, much as in the previous case. Preserving "France" means, in a collective consciousness, preserving French food, the French countryside, the French peasantry, and so on. French farmers do more than produce food; indeed, in purely economic terms French farmers are quite inefficient and costly, as the food they produce is much more expensive than food available from other sources. Part of what consumers pay for when they purchase food is 
the reproduction of the French countryside and an important part of the French population - not as individuals but as a segment with a set of cultural traits and extra-economic functions.

Rogers discusses three themes that have informed the thinking of French policy makers and politicians in this regard: "the maintenance of vital equilibria in society, occupation of the national territory..., and preservation of a cultivated landscape..." $(2000,56)$. Farmers are considered an important counterpart to a highly urbanized society, especially as the latter is perceived as dysfunctional in ways that the former is not (unemployment, crime, and so on). In addition, without farmers much of French territory would be "empty," unpopulated, and thus allegedly vulnerable to attack by foreign enemies or, in more recent conceptions, by wildlife or other apparently unwelcome ecological forces. Finally, small-scale farming is considered essential for the preservation of an orderly, aesthetically pleasing landscape; a wild, undisciplined land would be antithetical to French notions of "civilization."

As Rogers notes, this understanding of the functions of agriculture has led to proposals for a "two-speed agriculture." While large-scale factory-farming is seen as essential in a basic economic sense, there is also a desire to protect the place of those engaged in "social farming": "The other agriculture would be defined as a public good protected from market pressures...: agriculture de service as opposed to agriculture de production...." (Rogers 2000, 60). The language used to support such conceptions could hardly be more powerful: agriculture, especially of the peasant variety, is viewed as intimately connected with the "soul of the nation."

While the idea of a "two-speed agriculture" has remained only a proposal, actual agricultural policy has nonetheless been aimed at reproducing many more farmers than would be necessary in a strictly economic sense. A main goal of the European Union's Common Agricultural Policy has been "income parity," that is, ensuring that farmers' income remains on par with that of workers in other sectors, regardless of technological change or other economic 
factors (Franklin 1988). In other words, this form of support is designed to preserve a way of life that is not fully compatible with economic autonomy.

\section{Implications for conventional welfare recipients}

Treating welfare as a form of subsidy in the manner described here is enlightening in a variety of cases - including conventional recipients of welfare. Samuelson argues that Social Security and Medicare in the US act in part as a subsidy. For some people, these programs are a safety net against falling into poverty when they can no longer work. But some "older people are paid ... [merely] to stop working and enjoy themselves" (2005: A23): this may not be the "purpose" of the programs or those who created them, but it is a sensible description of their current function for many recipients. Samuelson invokes this language because he believes benefits should be cut for wealthy retirees, especially as increasing life expectancy enhances one's ability to work beyond a traditional retirement age. But the language makes sense even if one does not share that view: some people might well conclude that older people deserve this sort of subsidy. Either way, Samuelson's point has close affinities with the question addressed in this paper: should there be a public subsidy for older people - in this case to support a "culture of leisure"?

As for other conventional groups: recent research in the US suggests strongly that single parenthood is often an impediment to economic self-sufficiency for the poor. Harris (1996) found that a significant proportion of those leaving welfare (most of whom would be single parents) did not remain off welfare for long. One key factor that helped significantly in avoiding welfare "recidivism" was marriage/cohabitation; those who remained single had higher-thanaverage rates of return to welfare. To invoke the frame developed in this paper, we can consider single parenthood (mostly, single motherhood) as a way of life that might therefore be subsidized by the public. In reality, that formulation highlights how the dominant mode of welfare discourse 
rejects the legitimacy of such a subsidy, even if some of the support itself persists. ${ }^{9}$ As Phillips argues in her critique of Mead, "The driving force behind this policy [workfare] ... is not the wish to further the interests of women or children but outrage at women who depend on state largess to fund a lifestyle - lone parenthood - of which people disapprove" (1997: 123).

Making sense of this disapproval and its role in policy formation requires attention to culture - to the question of our attitudes toward diversity in ways of life and the role of public policy in preserving some of them. The problem cannot be addressed solely through traditional perspectives focusing on poverty, need, political mobilization, and so on. Instead, we need some leverage over the question: to what extent and in which instances are societies willing to preserve - and thus subsidize - ways of life that are incompatible with economic self-sufficiency?

For example, in relation to the core of the welfare population - single mothers - it will not work to say that welfare is "needed" in any absolute sense, that is, that the individuals who receive support are simply incapable of supporting themselves. The claim for social assistance contains implicit assumptions in this regard; the "need" is given in those assumptions, not in an irremediable incapacity. In particular, it is assumed it would be unreasonable to expect a mother to give up her children simply to become self-sufficient. Single mothers are (or would be) as a rule able to find jobs; many women in this category do so, especially if they are fortunate enough to have access to free childcare or an income sufficient to purchase it. For the rest, having responsibility for children is a significant obstacle to paid employment.

But it is not an insurmountable obstacle: one need only give up one's children. In a stroke, one's claim to public assistance vanishes, insofar as one is no longer different from the great mass of workers for whom children are not an impediment to employment. One can be self-sufficient along with all the rest. In other words, one need simply change one's way of life, become something other than what one is. Alternatively, one could find a marriage partner for 
purely economic reasons. The suggestions are by no means idle: one recent statement proposes that eliminating welfare would reduce out-of-wedlock births and lead some women to marry their sex partners; "In addition, some poor women who did still bear children out of wedlock would put the children up for adoption. Civil society should encourage that by eliminating the present regulatory and bureaucratic barriers to adoption" (Tanner 2003: 93).

Again, however, neither is widely considered a reasonable expectation; they do not inform policy in any jurisdiction I am aware of. No doubt Tanner is not alone in believing that people should not have (or keep) children they cannot support, but it is inconceivable that we would see a serious and viable legislative proposal to solve the "dependency" problem by removing millions of children from poor lone-parent households. Proposals for sterilization of welfare recipients and the "family cap," to prevent future dependency, go too far for most.

In other words, the demand for economic self-sufficiency has firm limits in practice. But theorists of welfare reform - and those advocating workfare, in particular - seem not to have determined precisely where those limits lie. This much is evident in the underdevelopment of the Mead passage quoted at the beginning of this paper. Nowhere does Mead make plain his rationale for stipulating 50 per cent employment for single mothers, as against, say, 75 or 25 per cent. The entire proposal has the feel of an afterthought; again, it comes in the final paragraph of his book, as a brief response to a critic.

This ambiguity has many roots, but the cultural aspect seems fundamental. In particular, many people would appear to believe, at least implicitly, that certain forms of life - such as caring for children when one does not have an income-generating partner - should not have to be abandoned for the sake of becoming economically self-sufficient. But that formulation isn't quite right, as consideration of recent welfare reform shows: some societies do sometimes insist that mothers of very small children take paid employment (often without guaranteeing the availability 
of decent child care). Moreover, requirements in this regard are different in different jurisdictions, for example, different American states. This is not the same as mandating that one give up one's children, but it does frequently contribute to poverty and hardship, words that have an inescapably negative connotation. Again: ambiguity.

But this ambiguity in practices is actually very instructive, when contrasted with the certainty that characterizes existing public discourses in which economic self-sufficiency is axiomatically the core value. The two primary examples in this paper show that societies are sometimes willing to subsidize ways of life that cannot reproduce themselves through market activities (paid employment) alone. This willingness is also apparent in relation to conventional welfare recipients. Even in the US, with its time limits and high degree of conditionality (requirements to participate in training and job-related activities), substantial exemptions enable large numbers of people to continue receiving support, despite significant campaigns to reduce or eliminate these subsidies. ${ }^{10}$ The real point, however, is that the issue is not examined in these terms: its cultural dimensions remain submerged by a fixation on economics.

\section{Conclusion}

Having developed a perspective from consideration of two "marginal" cases, we are in a position to draw insights regarding the core welfare populations and welfare debates more generally. Critics of welfare (those who would eliminate or reduce it) have a well-developed vocabulary in which concepts such as dependency and economic self-sufficiency are taken as clearly understood and obviously important. These concepts are rooted in a hegemonic discourse that connects with some of the normatively core institutions of western societies: markets and nuclear families, for example. People who adopt a different view - or who simply seek to clarify their thinking on the choices to be made - might find it harder to express an alternate 
perspective, precisely because it cannot draw on the hegemonic discourse. My goal here is to contribute to an alternate language: with concepts such as "welfare as a subsidy for a way of life that is incompatible with economic self-sufficiency" and "the cultural context of work" (in contrast to work as paid employment only).

Welfare is usually viewed as a topic with primarily economic and political dimensions. Whatever one's political perspective, the issue that preoccupies politicians and voters is economic self-sufficiency: across the political spectrum this is held to be a core value, the foundation of a proper social policy. Liberals (progressives) are understood to differ from conservatives only in the extent to which they are willing to provide public support to help people achieve the condition of self-sufficiency. But it is not admissible in public discourse to assert that lone motherhood is often simply incompatible with self-sufficiency (that is, when one has young children, an education that qualifies one only for low-paid jobs, and so on). People defined as "dependent" become subject to a demand that they change (Katz 1995). But that demand has also become contentious, especially when public discourse has also absorbed principles of multiculturalism.

Wealthy societies facilitate the continuation of diverse forms of life despite the failure of some to find buyers in markets. We live in highly marketized societies, but we do not use markets or market-oriented values for everything. ${ }^{11}$ The two examples discussed earlier in this paper are significant for the respective societies, but the list could no doubt be quickly multiplied. Moreover, some countries subsidize lone motherhood to a greater extent than others: a recent survey by Kilkey and Bradshaw (1999) demonstrates that lone mothers in some countries ${ }^{12}$ have below-average rates of poverty whether or not they are employed, because of direct subsidies or because social policy otherwise enables women to reconcile work and care demands. Ireland is especially noteworthy for the fact that rates of poverty are below average 
and lone mothers are predominantly occupied in full-time care (while lone mothers in the other six are predominantly employed, with the help of heavily subsidized child care).

Conventional welfare recipients are frequently not understood to do work that creates value for the society at large, in no small measure because key elements of the way of life of this population segment are considered objectionable. Members of the voting public can appreciate the difficulties of combining full-time employment at low wages with single parenthood and can probably understand as well that being a parent involves a great deal of actual work. But it is nonetheless easy for politicians to tap (or foment) a resentment deriving from the belief that people should not have children without being in stable relationships (that is, married, heterosexually). The problem is not rooted in lack of work; rather, the problem is rooted in a way of life that many find objectionable.

This point, on its own, is not new. The contribution here lies in the framing of that point in contrast to the way other welfare-receiving groups are successful in pressing their demands for subsidy - despite the fact that they too commit the principal sin (not "working") that ostensibly makes single mothers unworthy of public support. Public discourse concerning welfare would be more enlightening if we could move beyond hegemonic (economistic) notions concerning "work," "responsibility," and "dependency." The analysis in this paper leads to a suggestion that we engage what I believe is the central political question embedded in debates on welfare: to what extent are we willing to insist that everyone conform to demands for economic selfsufficiency, irrespective of the cultural variety that characterizes complex societies? We cannot make sense of our answers to the economic aspects of that question without also clarifying our thinking on the cultural aspects. 


\section{Notes}

${ }^{1}$ I am grateful to Tony Walter for suggesting this comparison, and to Manali Desai and the anonymous reviewers for their more general comments.

${ }^{2}$ This definition resonates with a well-elaborated discussion by Chilton, who defines cultures as "groups of people sharing ... a way of relating" (where "shared" is specified as "publicly common") (1988: 428-9).

${ }^{3}$ Arab families in Israel are also generally larger. Until 1993, Arabs were excluded, via formally neutral but nonetheless clearly targeted measures, from programs that provided additional support to large families (Rosenhek 1999). Arabs are still excluded from other kinds of subsidies, directed more carefully at Haredim.

${ }^{4}$ In 1995 there were approximately 130,000 ultra-Orthodox adults (>17) in Israel (based on LFS). This figure leads to a very rough estimate of 65,000 households. That number does not consider age structure; subtracting the elderly, the number of households with adults in the labor force age range would be lower. It is reasonable to conclude that approximately half of all ultraOrthodox households in Israel contain a male head who does not engage in paid labor (though some of these may work in unreported jobs).

${ }^{5}$ Whether full-time Torah study is traditional in a deep sense is debatable; in previous centuries full-time study was rare (Sheleg 2000). In addition, some elements of Jewish tradition stress the importance of "secular" activities that support Jewish communities; as an icon, Maimonides is an important figure in this regard, a renowned scholar who was also a well-known physician.

${ }^{6}$ Stadler also notes that this approach is resented by some younger members of the community, who blame community leaders for perpetuating their economic hardship. 
${ }^{7}$ Though not a "classic" peasantry; Moulin (1991) makes it clear that French peasants today are quite different from their predecessors.

${ }^{8}$ Nor does one suppose that subsidies to farmers make macro-economic sense.

${ }^{9}$ It is worth recalling that one of the original welfare programs - Survivors' Insurance - was designed precisely to enable some single mothers, that is, widows, to live without employment, so that they could continue to care for their own children in their own homes (Mink 1998).

${ }^{10}$ Here as well we see that there is continuity as well as change in developments regarding welfare. Global economic change has led to some retrenchment, but not to total transformation or elimination of programs.

${ }^{11}$ In fact it seems that a primary goal of an entire sub-discipline - economic sociology - is to demonstrate how limited and circumscribed our use of markets is.

${ }^{12}$ Belgium, Denmark, Finland, Luxemburg, Sweden, Norway, and Ireland.

\section{References}

Abercrombie, Nicholas, Hill, Stephen, and Turner, Bryan, 1984, The Penguin Dictionary of Sociology (London: Penguin).

Benería, Lourdes, 1988, Conceptualizing the labour force: the underestimation of women's economic activities, in: R. E. Pahl (Ed) On work: historical, comparative and theoretical approaches, Oxford: Basil Blackwell.

Berman, Eli, 2000, Sect, subsidy and sacrifice: an economist's view of ultra-orthodox Jews. Quarterly Journal of Economics, 115, 905-953.

Blau, Joel, and Abramovitz, Mimi, 2004, The dynamics of social welfare policy (Oxford: Oxford University Press). 
Brown, Michael, 1988, Remaking the welfare state: retrenchment and social policy in America and Europe (Philadelphia: Temple University Press).

Chilton, Stephen, 1988, Defining political culture. Western Political Quarterly, 41, 419-445.

Esping-Andersen, Gøsta, 1990, The three worlds of welfare capitalism (Princeton: Princeton University Press).

Feldman, Stanley and Zaller, John, 1992, The political culture of ambivalence: ideological responses to the welfare state. American Journal of Political Science, 36, 268-307.

Franklin, Michael, 1988, Rich man's farming: the crisis in agriculture (London: Routledge).

Harris, Kathleen Mullan, 1996, Life after welfare: women, work, and repeat dependency. American Sociological Review, 61, 407-426.

Heclo, Hugh, 1986, General welfare and two American political traditions. Political Science Quarterly, 101, 179-196.

Heilman, Samuel, 1992, Defenders of the faith: inside ultra-orthodox Jewry (Berkeley: University of California Press).

Hochschild, Arlie, 1990, The second shift: working parents and the revolution at home (London: Piatkus).

Huber, Evelyne, and Stephens, John, 2001, Development and crisis of the welfare state: parties and policies in global markets (Chicago: University of Chicago Press).

Ilan, Shahar, 2000, Haredim Ltd: Budgets, Draft-dodging, and Law-breaking (Haredim be-'a.m.: ha-taktsivim, ha-hishtamtut ve-remisat ha-hok) (Jerusalem: Keter, in Hebrew).

Katz, Michael B., 1995, Improving poor people: the welfare state, the "underclass, " and urban schools as history (Princeton: Princeton University Press). 
Mead, Lawrence, 1997, From welfare to work: lessons from America (London: IEA Health and Welfare Unit).

Mink, Gwendolyn, 1998, Welfare's end (Ithaca: Cornell University Press).

Mishra, Ramesh, 1999, Globalization and the Welfare State (Cheltenham: Edward Elgar).

Moulin, Annie, 1991, Peasantry and society in France since 1789, Translated by M.C. Cleary and M.F. Cleary (Cambridge: Cambridge University Press).

Murray, Charles, 1984, Losing ground: American social policy, 1950-1980 (NY: Basic Books). Phillips, Melanie, 1997, Workfare for lone mothers: a solution to the wrong problem?, in: Lawrence M. Mead (Ed) From welfare to work: lessons from America, London: IEA Health and Welfare Unit.

Rogers, Susan Carol, 2000, Farming visions: culture and agriculture in France. French Politics, Culture \& Society, 18, 50-70.

Rosenhek, Zeev, 1999, The exclusionary logic of the welfare state: Palestinian citizens in the Israeli welfare state. International Sociology, 14, 195-215.

Samuelson, Robert, 2005, Cut my benefits. Washington Post, 9 February, p. A23.

Sheleg, Yair, 2000, The new religious Jews: recent developments among observant Jews in Israel (HaDati'im haHadashim: Mabat achshavi al haHevra haDatit b'Yisrael) (Jerusalem: Keter, in Hebrew).

Stadler, Nurit, 2002, Is profane work an obstacle to salvation? The case of ultra-Orthodox (Haredi) Jews in contemporary Israel. Sociology of Religion, 63, 455-474.

Tanner, Michael, 2003, The poverty of welfare: helping others in civil society (Washington DC: The Cato Institute). 